\title{
Can perioperative haemodynamics and opioid requirement in Abdominal Hysterectomy be influenced by a premedication drug?
}

\author{
M. Paul Wilson ${ }^{1}$, Usha Christopher ${ }^{2}$
}

\begin{abstract}
${ }^{1}$ Department of Anaesthesiology, ${ }^{2}$ Department of Obstetrics and Gynaecology, Dr. Somervell Memorial CSI Medical College and Hospital, Karakonam 695504, Kerala, India
\end{abstract}

Received: 28 October 2016

Accepted: 02 November 2016

\section{*Correspondence:}

Dr. M. Paul Wilson,

E-mail: paulwilson555@gmail.com

Copyright: ( ) the author(s), publisher and licensee Medip Academy. This is an open-access article distributed under the terms of the Creative Commons Attribution Non-Commercial License, which permits unrestricted non-commercial use, distribution, and reproduction in any medium, provided the original work is properly cited.

\section{ABSTRACT}

Background: Abdominal hysterectomy is a common surgery, usually done under Spinal anaesthesia. It would be greater if a premedication oral drug were available to reduce the perioperative use of opioids. The aim of the study was to find out whether gabapentin can reduce the perioperative dose of tramadol but without affecting perioperative haemodynamics.

Methods: This is a randomized double blinded controlled study. Patients undergoing Abdominal hysterectomy under Spinal anaesthesia were divided into two groups. One group was given gabapentin and another was given placebo as premedication drugs. Perioperative haemodynamics were monitored. Perioperative requirement of tramadol injection was estimated.

Results: No significant changes were noted in perioperative haemodynamics. Perioperative requirement of tramadol was reduced in gabapentin group.

Conclusions: Gabapentin does not affect perioperative haemodynamics. Gabapentin reduces perioperative requirement of tramadol.

Keywords: Abdominal hysterectomy, Gabapentin, Intraoperative haemodynamics

\section{INTRODUCTION}

Pain during perioperative period affects the recovery from anesthesia and surgery. ${ }^{1}$ The most common reasons of prolonged recovery are drowsiness, sedation, vomiting, nausea and pain. ${ }^{2}$ Opioids are used during perioperative period in several patients. ${ }^{3,4}$ The limitations of opioids include their side effects. Also not all patients respond well to opioids. Several mechanisms are involved in perioperative pain. ${ }^{5}$ So it is better to combine opioid and non-opioid analgesic drugs. This will result in efficient analgesia. ${ }^{6}$ There will be a reduction of opioid requirement also. Thus we will be able to avoid the side effects of opioids to a greater extent. ${ }^{7}$ Also we will be able to avoid opioids tolerance.
The chemical structures of gabapentin and $\gamma$ aminobutyric acid are similar. But gabapentin does not interact with GABA receptors. The concentration of GABA in the brain is increased by gabapentin. It is used as an anticonvulsant drug. ${ }^{8}$ Gabapentin is also used in diabetic neuropathy, reflex sympathetic dystrophy, postherpetic neuralgia and neuropathic pain.-12 The development of hyperalgesia can be avoided by pretreatment with gabapentin. ${ }^{13}$ One of the major causes for postoperative pain is central neuronal sensitization. ${ }^{14}$ Gabapentin acts very specifically on the neural mechanisms related to central neuronal sensitization.

Oral gabapentin as a single dose reduces postoperative opioid consumption..$^{15}$ The aim of our study is to find out the effects of gabapentin on several factors in patients 
who are undergoing total abdominal hysterectomy. Such factors are intraoperative surgical environment, intraoperative haemodynamics, early postoperative pain and overall perioperative tramadol requirement.

\section{METHODS}

\section{Aims and Objectives}

To assess the effect of gabapentin when given as a premedication drug on perioperative haemodynamics, perioperative pain and perioperative requirement of tramadol.

\section{Design}

The permission and consent of the Institutional Ethics Committee was obtained.Written informed consents were received from all the patients. Female patients posted for elective total abdominal hysterectomy under spinal anaesthesia were included in the study. Sixty patients were selected. They were of ASA Grade I or II, weighed above $40 \mathrm{~kg}$ and aged above 30 years. The patients with any of the following disorders were excluded from the study- allergy to tramadol or gabapentin, contraindications to tramadol or gabapentin, bleeding disorders, peptic ulcer, asthma or renal impairment.

\section{Sample size}

The sample size was calculated as 60 patients in total. The study was a randomized and double blinded clinical trial. Patients were randomly divided with the help of slip in box protocol. There were two groups with 30 patients in each.

Two hours before surgery gabapentin was given as an oral tablet of $300 \mathrm{mg}$ to patients in the gabapentin group. Placebo tablet was given to the patients in the other group. In the operation theatre, an $18 \mathrm{G}$ peripheral venous cannula was inserted in to a wide and straight vein over the dorsum of hand. Isotonic saline infusion was started. Spinal anaesthesia was performed with sub arachnoid injection of $25 \mu \mathrm{g}$ fentanyl and $3.5 \mathrm{ml}$ of $0.5 \%$ hyperbaric bupivacaine. The following variables were monitored heart rate $(\mathrm{HR})$, peripheral oxygen saturation $\left(\mathrm{SpO}_{2}\right)$, systolic arterial pressure (SAP), diastolic arterial pressure (DAP) and mean arterial blood pressure (MAP).

Post operative pain was assessed with the aid of Visual Analogue Scale (VAS). In VAS, $0 \mathrm{~cm}=$ no pain and 10 $\mathrm{cm}=$ severe pain. During pre anaesthetic assessment, VAS was explained to the patients. Intravenous tramadol was administered to alleviate post operative pain. All the patients received intravenous tramadol post operatively. First dose of tramadol was $50 \mathrm{mg}$. After that as per patient's demand, every time $25 \mathrm{mg}$ tramadol was given but at an interval of greater than 30 minutes. Also it was made sure that tramadol never exceeded $400 \mathrm{mg}$ over a period of 4 hours. An anaesthetist not involved in the study assessed the patients. Evaluation was done at 2 hours, 4 hours, 8 hours, 12 hours, and 24 hours. Evaluation was done for sedation, intensity of pain, tramadol requirement and total perioperative tramadol consumption. Haemodynamic vital parameters viz., heart rate, respiratory rate, $\mathrm{SpO}_{2}$ and blood pressure were recorded. The presence or absence of side effects was also noted. The side effects noted were sedation, nausea and vomiting. All the sixty patients took part in the study. Data was analyzed using Wilcoxon- Mann- Whitney test and Fisher Exact Test. Data was considered as significant if $\mathrm{p} \leq 0.05$.

\section{Statistical analysis}

Statistical analysis was done with the SPSS software. Demographic data was analyzed for the comparability of both groups. Age and weight were compared using Wilcoxon- Mann- Whitney test. ASA status was compared using Fisher Exact Test. Intra operative haemodynamic variables were compared using Wilcoxon- Mann- Whitney test. Analgesic requirement and VAS score over 24-hour period were analyzed with Wilcoxon- Mann- Whitney test. A 'p' value of $<0.05$ was considered to be statistically significant.

\section{RESULTS}

The groups could be comparable with respect to the age (Table 1).

Table 1: Comparison of sample based on age.

\begin{tabular}{|lllll|}
\hline Parameter & $\begin{array}{l}\text { Placebo } \\
\text { (Sum of } \\
\text { ranks) }\end{array}$ & $\begin{array}{l}\text { Gabapentin } \\
\text { (Sum of } \\
\text { ranks) }\end{array}$ & $\begin{array}{l}\text { U } \\
\text { statistic }\end{array}$ & p value \\
\hline Age & 794.5 & 1035.5 & 329.5 & 0.074827 \\
\hline
\end{tabular}

Since the $p$-value is $\geq 0.05$, the groups can be comparable with respect to the age.

The groups were comparable with respect to weight (Table 2).

Table 2: Comparison of sample based on weight.

\begin{tabular}{|lllll|} 
Parameter & $\begin{array}{l}\text { Placebo } \\
\text { (Sum of } \\
\text { ranks) }\end{array}$ & $\begin{array}{l}\text { Gabapentin } \\
\text { (Sum of } \\
\text { ranks) }\end{array}$ & $\begin{array}{l}\text { U } \\
\text { statistic }\end{array}$ & p value \\
\hline Weight & 933 & 897 & 432 & 0.790147 \\
\hline
\end{tabular}

Since the $p$-value is $\geq 0.05$, the groups can be comparable with respect to the weight.

The groups were comparable with respect to ASA status (Table 3). 
Table 3: Comparison of sample based on ASA status.

\begin{tabular}{|c|c|c|c|}
\hline \multicolumn{4}{|c|}{ Fisher exact test } \\
\hline & Placebo & Gabapentin & $\begin{array}{l}\text { Marginal } \\
\text { row totals }\end{array}$ \\
\hline ASA I & 19 & 17 & 36 \\
\hline ASA II & 11 & 13 & 24 \\
\hline $\begin{array}{l}\text { Marginal } \\
\text { column totals }\end{array}$ & 30 & 30 & $\begin{array}{l}60(\text { Grand } \\
\text { Total) }\end{array}$ \\
\hline
\end{tabular}

The Fisher exact test statistic value is 0.792494 . The result is not significant at $\mathrm{p}<0.05$. Hence the groups were comparable with respect to ASA status.

The groups were comparable with respect to intra operative haemodynamic variables (Table 4).

Since the $p$-value is $\geq 0.05$, the groups can be comparable with respect to the intra operative haemodynamic variables. Statistically there is no significant difference in the intra operative haemodynamics between two groups. Thus we can infer that gabapentin does not influence intra operative haemodynamics.

Table 4: Comparison of sample based on intra operative haemodynamic variables.

\begin{tabular}{|lllll|}
\hline Parameter & $\begin{array}{l}\text { Placebo } \\
\text { (Sum of } \\
\text { ranks) }\end{array}$ & $\begin{array}{l}\text { Gabapentin } \\
\text { (Sum of } \\
\text { ranks) }\end{array}$ & $\begin{array}{l}\text { U } \\
\text { statistic }\end{array}$ & p value \\
\hline Heart rate & 885.5 & 944.5 & 420.5 & 0.662735 \\
\hline $\begin{array}{l}\text { Systolic } \\
\text { Bp (SAP) }\end{array}$ & 944.5 & 885.5 & 420.5 & 0.662735 \\
\hline $\begin{array}{l}\text { Diastolic } \\
\mathrm{Bp}^{(D A P)}\end{array}$ & 944 & 886 & 421 & 0.668106 \\
\hline $\mathrm{SpO}_{2}$ & 900.5 & 929.5 & 435.5 & 0.830255 \\
\hline
\end{tabular}

Post-operative pain was assessed using the Visual Analogue Scale. It was observed that the Gabapentin group showed lower scores at 2, 4, 8, 12 and 24 hours consistently following surgery.

Table 5: Comparison of VAS.

\begin{tabular}{|c|c|c|c|c|c|c|c|}
\hline \multirow{2}{*}{$\begin{array}{l}\text { Parameter } \\
\text { (VAS Score) }\end{array}$} & \multicolumn{3}{|c|}{ Placebo } & \multicolumn{3}{|c|}{ Gabapentin } & \multirow[b]{2}{*}{ p value } \\
\hline & Mean & SD & Sum of ranks & Mean & SD & Sum of ranks & \\
\hline 2 hours & 6.0 & 1.0 & 1112.5 & 5.2 & 0.9 & 717.5 & 0.003501 \\
\hline 4 hours & 5.9 & 1.2 & 1138.5 & 4.9 & 1.0 & 691.5 & 0.000952 \\
\hline 8 hours & 4.5 & 0.9 & 1068 & 3.9 & 0.9 & 762 & 0.023696 \\
\hline 12 hours & 4.0 & 0.9 & 1141 & 3.2 & 0.9 & 689 & 0.000834 \\
\hline 24 hours & 3.3 & 1.0 & 1061.5 & 2.7 & 1.0 & 768.5 & 0.030317 \\
\hline
\end{tabular}

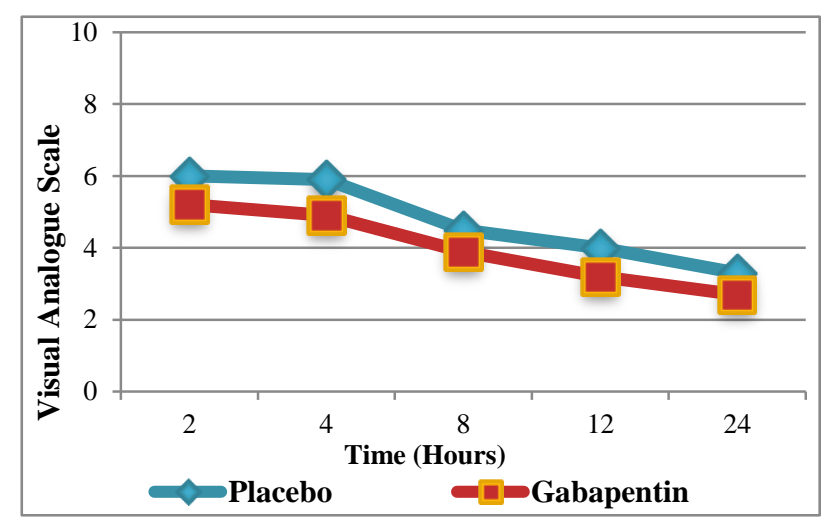

Figure 1: Comparison of VAS scores.
Consistently the p-value is $\leq 0.05$. So the difference between placebo and gabapentin is statistically significant.

The analgesic requirement was also assessed at 0-2, 2-4, 4-8, 8-12 and 12-24 hours following surgery. Gabapentin group showed lower tramadol consumption consistently at all-time intervals (Table 6).

The p- value is $\geq 0.05$ for $0-2$ and $12-24$ hours which is statistically not significant.

Table 6: Comparison of tramadol requirement.

\begin{tabular}{|llllllll|}
\hline $\begin{array}{l}\text { Parameter (Tramadol } \\
\text { requirement) }\end{array}$ & Placebo & \multicolumn{7}{c|}{ Gabapentin } \\
\hline 0-2 hours & 80.8 & 15.7 & 1016 & 72.5 & 16.5 & 814 & 0.135378 \\
\hline 2-4 hours & 98.3 & 27.8 & 1182.5 & 70.0 & 19.0 & 647.5 & 0.000077 \\
\hline 4-8 hours & 64.2 & 15.7 & 1165.5 & 45.0 & 17.9 & 664.5 & 0.000213 \\
\hline 8-12 hours & 61.7 & 17.0 & 1267.5 & 32.5 & 11.7 & 562.5 & 0.000000 \\
\hline 12 -24 hours & 59.2 & 13.9 & 1034 & 50.0 & 20.8 & 796 & 0.078519 \\
\hline Total & 363.3 & 51.2 & 1275 & 270.0 & 49.3 & 555 & 0.000000 \\
\hline
\end{tabular}


The $\mathrm{p}$ - value is $\leq 0.05$ for $2-4,4-8,8-12$ hours and total requirement of tramadol. This is statistically significant.

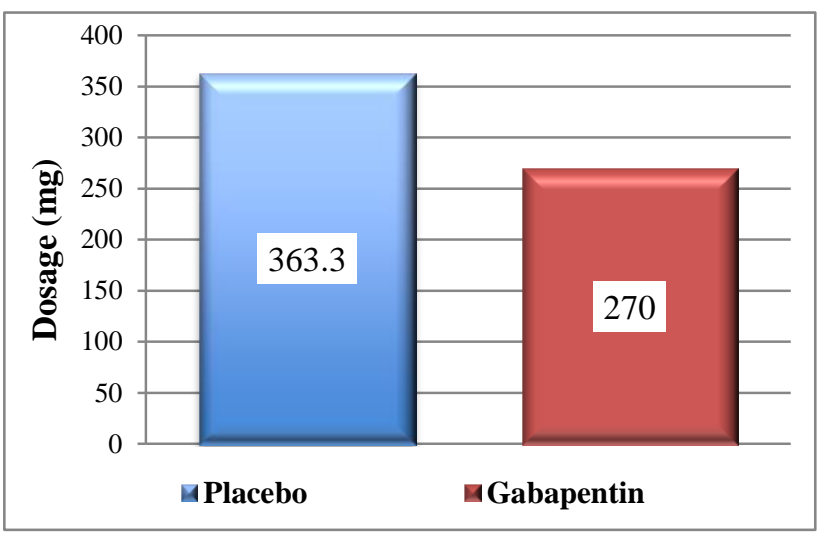

Figure 2: Comparison of tramadol requirement.

The side effects noted were nausea, vomiting and sedation.

Table 7: Side effects.

\begin{tabular}{|lll|}
\hline & Placebo & Gabapentin \\
\hline Nausea & 4 & 3 \\
\hline Vomiting & 1 & 0 \\
\hline Sedation & 3 & 4 \\
\hline
\end{tabular}

We compared the incidence of side effects between both the groups. It was not significant.

\section{DISCUSSION}

Our clinical trial was studying the effects of gabapentin premedication in patients who were undergoing total abdominal hysterectomy under spinal anaesthesia. We could not find any significant difference in surgical environment or intraoperative haemodynamics. But postoperative pain scores and perioperative total tramadol consumption got reduced by gabapentin premedication. Also there were not much side effects with gabapentin premedication.

When different analgesic drugs are combined, the analgesic effect gets augmented. ${ }^{16}$ The doses of individual drugs can be reduced. Thus we can minimise the side effects of the drugs. This is possible by combining analgesics which have different locations of actions. $^{17}$ One of the commonest drugs used for postoperative pain relief is tramadol. Tramadol acts by stimulating $\mu$ opioid receptors. Tramadol also acts on the noradrenergic and serotonergic systems. By this action, tramadol inhibits the reuptake of serotonin and norepinephrine. Due to the two different mechanisms of action, tramadol is an effective analgesic drug. ${ }^{18}$

Gabapentin reduces hypersensitivity associated with inflammation, nerve injury and postoperative pain. ${ }^{19}$
Central neuronal sensitization is one of the mechanisms of hyperalgesia. Postoperative pain to some extent results from central neuronal sensitization. ${ }^{20}$ Gabapentin is an antihyperalgesic drug. It can very well be used for the alleviation of perioperative pain. When combined with another analgesic drug, gabapentin produces augmented analgesia. Thus gabapentin amplifies the analgesic effects of tramadol. ${ }^{21}$ The combination of gabapentin and tramadol produces better analgesia than with tramadol alone.

For patients who underwent abdominal hysterectomy, during the post operative period gabapentin markedly decreases pain. ${ }^{22}$ Also gabapentin to a greater extent reduces tramadol administration. In our study we could find that there was a reduction in pain scores for a period of 24 hours.

Some of the prevalent analgesics in the postoperative pain management are nonsteroidal anti-inflammatory drugs (NSAIDs). NSAIDs reduce postoperative pain. They also reduce the postoperative consumption of opioids. They are well known, potent, and less expensive. Since NSAIDs have adverse renal, gastrointestinal and haemostatic effects in some patients, their role is limited in some situations. ${ }^{23,24}$ Gabapentin is a less well known drug. To make use of gabapentin widely, we have to prove several things about gabapentin. We have to prove that it significantly reduces opioid consumption. We have to prove that it provides better pain relief than NSAIDs. Also we have to prove that gabapentin has fewer adverse effects. $^{25}$

Turan et al studied the patients who underwent abdominal hysterectomy. ${ }^{26}$ They studied the effect of gabapentin $1200 \mathrm{mg}$ on postoperative pain. They also monitored tramadol consumption. Both pain and tramadol consumption got reduced in the gabapentin group. In our study we used only $300 \mathrm{mg}$ dose of gabapentin. However patients had a comfortable level of analgesia preoperatively. Also the side effects caused by the high dosage of gabapentin are much less in our study.

Durmus et al studied the patients who underwent abdominal hysterectomy. ${ }^{27}$ They assessed the effects of gabapentin and acetaminophen. The patients were given drugs one hour before surgery. One group received 1200 $\mathrm{mg}$ gabapentin. Another group received acetaminophen $20 \mathrm{mg}$ per $\mathrm{kg}$ with $1200 \mathrm{mg}$ gabapentin. Third group received placebo. The pain score between the gabapentin and gabapentin plus acetaminophen group did not differ significantly. So ultimately the authors suggested only gabapentin and not any combination with acetaminophen.

$1200 \mathrm{mg}$ gabapentin and placebo were compared in abdominal hysterectomy patients by Dierking et al. ${ }^{28}$ The drugs were given one hour before surgery. There was significant reduction of pain in gabapentin group. Also the incidences of side effects viz., nausea and vomiting were less. In our study, there minimal side effects. 
Elective vaginal hysterectomy patients were studied by Rorarius et al. ${ }^{29}$ They gave gabapentin $1200 \mathrm{mg}$ to one group. Another group was given oxazepam $15 \mathrm{mg}$. In the initial postoperative hours gabapentin reduced patientcontrolled analgesia by $40 \%$. Comparing with gabapentin group, the placebo group had more pain during the initial postoperative period. In our study also we got similar findings.

Fassoulaki et al studied the nature and course of postoperative pain for five days and much more. ${ }^{30}$ For one group they gave gabapentin $600 \mathrm{mg}$. For another group they gave placebo. The drugs were started 18 hours preoperatively. The drugs were repeated $6^{\text {th }}$ hourly till five days. Morphine was also given for three days. The patients were followed for one month postoperatively. Gabapentin decreases morphine consumption for two days only. After 48 hours, could not have any impact on the pain. So we can know that gabapentin usage is limited to early post operative period only. Gabapentin is a good choice for perioperative usage.

Frouzanfard et al compared gabapentin $1200 \mathrm{mg}$ and placebo in hysterectomy patients. ${ }^{31}$ In the gabapentin group, pain and morphine consumption decreased significantly. In the immediate postoperative period few side effects were noted. The side effects included nausea and vomiting. These side effects were attributed to the high dosage of gabapentin. In our study gabapentin was given at a dose of $300 \mathrm{mg}$. The lesser incidence of side effects in our study could be attributed to the smaller dose of gabapentin.

Patients tolerate the single dose of gabapentin well. Gabapentin has fewer side effects. The drug interactions are less for gabapentin. When gabapentin is given as single small dose say $300 \mathrm{mg}$, the side effects are not very significant. Thus, gabapentin can be a very good premedication drug. The ideal time for the gabapentin premedication is one to two hours preoperatively. By this way we can get the maximum effect of gabapentin premedication at the required and most appropriate time.

\section{CONCLUSION}

We conclude that a single oral premedication of gabapentin does not interfere with perioperative haemodynamics. Also preoperatively gabapentin increases the analgesic effect of tramadol and decreases tramadol consumption. Gabapentin at single oral dose of $300 \mathrm{mg}$ does not create any significant side effect. So gabapentin is a good choice as the premedication drug.

\section{ACKNOWLEDGEMENT}

We thank research coordinators, nursing staff and statisticians.

Funding: No funding sources Conflict of interest: None declared
Ethical approval: The study was approved by the Institutional Ethics Committee

\section{REFERENCES}

1. Usichenko TI, Röttenbacher1 I, Kohlmann T, Jülich A, Lange J, Mustea A, et al. Implementation of the quality management system improves postoperative pain treatment: a prospective pre-/post-interventional questionnaire study. Br. J. Anaesth. 2013;110(1):8795.

2. Imani F, Gabapentinoids RP. Gabapentin and pregabalin for postoperative pain management. Anesth Pain Med. 2012;2(2):52-3.

3. VanDenKerkhof, Elizabeth G. Impact of Perioperative Pain Intensity, Pain Qualities, and Opioid Use on Chronic Pain after Surgery: A Prospective Cohort Study. Regional Anesthesia and Pain Medicine: 2012;37(1):19-27.

4. Chang CY, Challa CK, Shah J, Eloy JD. Gabapentin in acute postoperative pain management. Biomed Res Int. 2014:631756.

5. Rivat, Cyril, Bollag, Laurent, Richebé, Philippe. Mechanisms of regional anaesthesia protection against hyperalgesia and pain chronicization. Current Opinion in Anaesthesiology. 2013;26(5):621-5.

6. Potter JS, Marino EN, Hillhouse MP, Nielsen S. Buprenorphine/Naloxone and Methadone Maintenance Treatment Outcomes for Opioid Analgesic, Heroin, and Combined Users: Findings From Starting Treatment With Agonist Replacement Therapies (START). Journal of Studies on Alcohol and Drugs. 2013;74(4):605-13.

7. Funk, Robert D, Hilliard, Paul. Perioperative Opioid Usage: Avoiding Adverse Effects. Plastic and Reconstructive Surgery. 2014;134(4S-2):32S-9S.

8. Holmes LB, Hernandez-Diaz S. Newer anticonvulsants: Lamotrigine, topiramate and gabapentin. Wiley Online Library. 2012;94(8):599606.

9. Calandre EP, Rico-Villademoros F, Slim M. Alpha 2 delta ligands, gabapentin, pregabalin and mirogabalin: a review of their clinical pharmacology and therapeutic use. Expert Review of Neurotherapeutics. 2016:1-15.

10. Hill CM, Balkenohl M, Thomas DW, Walker R, Mathe H, Murray G. Pregabalin in patients with postoperative dental pain. Eur J Pain. 2001;5(2):11924.

11. Ho KY, Gan TJ, Habib AS. Gabapentin and postoperative pain- -a systematic review of randomized controlled trials. Pain. 2006;126(1-3):91101 .

12. Tiippana EM, Hamunen K, Kontinen VK, Kalso E. Do surgical patients benefit from perioperative gabapentin/pregabalin? A systematic review of efficacy and safety. Anesth Analg. 2007;104(6):1545-56.

13. Stoicea N, Russell D, Weidner G, Durda M. Opioidinduced hyperalgesia in chronic pain patients and the 
mitigating effects of gabapentin. Front Pharmacol. 2015;6:104.

14. Nijs J, Malfliet A, Ickmans K, Baert I, Meeus M. Treatment of central sensitization in patients with 'unexplained' chronic pain: an update. Expert Opinion on Pharmacotherapy. 2014;15(12):1671-83.

15. Clarke HA, Katz J, McCartney CJL, Stratford P, Kennedy D, Pagé MG, et al. Kay. Perioperative gabapentin reduces $24 \mathrm{~h}$ opioid consumption and improves in-hospital rehabilitation but not postdischarge outcomes after total knee arthroplasty with peripheral nerve block. Br. J. Anaesth. 2014;113(5):855-64.

16. Lunn, Haxholdt t. Response: design challenges in trials of multimodal analgesia. Pain. 2016;157(1):281.

17. Jakobsson JG. Pain Management in Ambulatory Surgery-A Review. Pharmaceuticals. 2014;7(8):85065.

18. Scott LJ, Perry CM. Tramadol - A Review of its Use in Perioperative Pain. Drugs. 2000;60(1):139-76.

19. Tanabe M, Takasu K, Takeuchi Y, Ono H. Pain relief by gabapentin and pregabalin via supraspinal mechanisms after peripheral nerve injury. Journal of Neuroscience Research. 2008;86(15):3258-64.

20. Hansson, Per. Translational aspects of central sensitization induced by primary afferent activity: What it is and what it is not. Pain. 2014;155(10):1932-4.

21. Miranda HF, Noriega V, Prieto JC. Antinociceptive Interaction of Tramadol with Gabapentin in Experimental Mononeuropathic Pain. Basic and Clinical Pharmacology and Toxicology. 2016;119(2):210-4.

22. Turan A, Karamanlıog ${ }^{\complement}$ lu B, Memis D, Usar P, Pamukc Z, Mevlu“ t Tu“ re. The Analgesic Effects of Gabapentin After Total Abdominal Hysterectomy. Anesth Analg. 2004;98:1370-3.

23. Harirforoosh S, Asghar W, Jamali F. Adverse effects of nonsteroidal antiinflammatory drugs: an update of gastrointestinal, cardiovascular and renal complications. J Pharm Pharm Sci. 2013;16(5):82147.
24. Harirforoosh S, Jamali F. Renal adverse effects of nonsteroidal anti-inflammatory drugs: Expert Opinion on Drug Safety. 2009;8(6).

25. Gritsenko K, Khelemsky Y, Kaye AD, Vadivelu N, Urman RD. Multimodal therapy in perioperative analgesia. Clinical Anaesthesiology. March 2014;28(1):59-79.

26. Turan A, Kaya G, Karamanlioglu B, Pamukcu Z, Apfel CC. Effect of oral gabapentin on postoperative epidural analgesia. Br J Anaesth. 2006;96(2):242-6.

27. Durmus M, But KA, Saricicek V, Ilksen TH, Ersoy OM. The post-operative analgesic effects of a combination of gabapentin and paracetamol in patients undergoing abdominal hysterectomy: a randomized clinical trial. Acta Anaesthesiol Scand. 2007;51(3):299-304.

28. Dierking G, Duedahl TH, Rasmussen ML, Fomsgaard JS, Moiniche S, Romsing J, et al. Effects of gabapentin on postoperative morphine consumption and pain after abdominal hysterectomy: a randomized, double-blind trial. Acta Anaesthesiol Scand. 2004;48(3):322-7.

29. Rorarius MG, Mennander S, Suominen P, Rintala S, Puura A, Pirhonen R, et al. Gabapentin for the prevention of postoperative pain after vaginal hysterectomy. Pain. 2004;110(1-2):175-81

30. Fassoulaki A, Melemeni A, Tsaroucha A, Paraskeva A. Perioperative pregabalin for acute and chronic pain after abdominal hysterectomy or myomectomy: a randomised controlled trial. Eur J Anaesthesiol. 2012;29(11):531-6.

31. Frouzanfard F, Fazel MR, Abolhasani A, Fakharian E, Mousavi G, Moravveji A. Effects of gabapentin on pain and opioid consumption after abdominal hysterectomy. Pain Res Manag. 2013;18(2):94-6.

Cite this article as: Wilson MP, Christopher U. Can perioperative haemodynamics and opioid requirement in Abdominal Hysterectomy be influenced by a premedication drug? Int J Reprod Contracept Obstet Gynecol 2016;5:4210-5. 